\title{
Modulation of Pulmonary Cytochrome P4501A1 Expression by Hyperoxia and Inhaled Nitric Oxide in the Newborn Rat: Implications for Lung Injury
}

\author{
XANTHI I. COUROUCLI, YAN-HONG WEI, WEIWU JIANG, KATHIRVEL MUTHIAH, LEE W. EVEY, \\ ROBERTO BARRIOS, AND BHAGAVATULA MOORTHY
}

\begin{abstract}
Department of Pediatrics [X.I.C, Y.-H.W., K.M., B.M.], Baylor College of Medicine, Houston, Texas 77030; Department of Respiratory Care/Physical Medicine and Rehabilitation [L.W.E], Texas Children's Hospital, Houston, Texas 77030; Department of Pathology [R.B.], The Methodist Hospital, Houston, Texas 77030
\end{abstract}

\begin{abstract}
Inhaled nitric oxide (iNO), with supplemental oxygen, is used in the treatment of hypoxic respiratory failure of the newborn. In this study, we tested the hypothesis that exposure of newborn rats to iNO, hyperoxia, or iNO + hyperoxia would modulate the expression of pulmonary cytochrome P450 (CYP)1A1 in relation to acute lung injury. Newborn Fischer 344 rats were maintained in room air, or exposed to iNO, hyperoxia ( $>95 \%)$, or iNO (20 or $40 \mathrm{ppm})+$ hyperoxia for up to $168 \mathrm{~h}$, and lung injury parameters and CYP1A1 expression were studied. Animals given iNO (40 ppm) + hyperoxia were more susceptible to lung injury than those exposed to hyperoxia or iNO alone. On the other hand, animals exposed to iNO (20 ppm) + hyperoxia did not elicit lung damage. Pulmonary CYP1A1 protein and mRNA expression were induced by hyperoxia, iNO (20 or 40 ppm), or iNO (20 ppm) + hyperoxia for up to $168 \mathrm{~h}$, compared with air-breathing controls. In animals given iNO (40 ppm) + hyperoxia, pulmonary CYP1A1 was enhanced at $48 \mathrm{~h}$, followed by downregulation at later time points. Immunohistochemistry experiments showed localization of CYP1A1 in the pulmonary epithelial and endothelial cells. In conclusion, because previous studies have shown beneficial effects of CYP1A1 induction in hyperoxic lung injury, our current observations showing maintenance of pulmonary CYP1A1 induction by iNO $(20 \mathrm{ppm})+$ hyperoxia through the 168 -h period support the hypothesis that this phenomenon may contribute to the protective effects of iNO against hyperoxic injury. (Pediatr Res 59: 401-406, 2006)
\end{abstract}

$\mathrm{S}_{\mathrm{tu}}^{\mathrm{up}}$ upplemental oxygen therapy is routinely needed for the treatment of hypoxic respiratory failure, which is frequently encountered in preterm and term infants with respiratory distress and in older patients with acute respiratory distress syndrome (1). However, hyperoxic therapy may contribute to tissue damage and the development of lung diseases such as bronchopulmonary dysplasia (BPD) in preterm infants (2). Exposure of experimental animals to hyperoxia causes lung injury, and ROS (e.g. superoxide anion, hydrogen per-

Received January 19, 2005; accepted October 11, 2005.

Correspondence: Xanthi I. Couroucli, M.D., Baylor College of Medicine, 6621 Fannin, F.C. 530.01, Houston, TX 77030; e-mail: xanthic@bcm.tmc.edu

This work was supported in part by KO8 HL04333 to X.I.C., and grants RO1 ES009132 and RO1 HL070921 from the National Institutes of Health and American Heart Association (Texas Affiliate) grant (\#0355075Y) to B.M. oxide, and hydroxyl radical) are the most likely candidates to cause tissue injury $(2,3)$.

iNO, in conjunction with supplemental oxygen, is used for the treatment of neonatal pulmonary hypertension associated with hypoxic respiratory failure (4-6). Studies with iNO in experimental animals have shown that iNO exposures alone or in combination with various oxygen concentrations can attenuate the pulmonary vascular permeability associated with lung injury and improve survival in oxygen (7-9). In fact, iNO has been shown to be a selective and potent pulmonary vasodilator in humans (10). Howlett et al. (11) showed that hyperoxia in conjunction with iNO at 20 ppm increases the survival time in oxygen and reduces vascular leak and inflammatory activation in adult rats (11), and the protective effect of iNO is attributable to its ability to block pulmonary apoptosis. NO can react with lipid peroxyl radicals to prevent lipid peroxidation (12), and this might help protect against oxygen toxicity $(8,9)$. Garat et al. (13) demonstrated that $10 \mathrm{ppm}$ of iNO prevented the hyperoxia-induced increase in lipid peroxidation and lung WW/DW ratios in adult rats. In a recent study, Lin et al. (14) showed that iNO at $10 \mathrm{ppm}$ enhances distal lung growth in rats exposed to hyperoxia in the neonatal period.

On the other hand, some studies have shown exacerbation of oxygen-induced lung injury by iNO (13-15). Garat et al. (13) showed that inhalation of $100 \mathrm{ppm}$ iNO and hyperoxia increased vacular permeability to protein. Production of ROS and reactive nitrogen species that injure cells by lipid peroxidation, protein, and DNA damage is one of the major causes of tissue injury caused by prolonged exposure to high concentrations of oxygen and iNO (15). It is known that high $\mathrm{O}_{2}$ increases production of superoxide (15), which could react spontaneously with NO to form peroxynitrite, resulting in toxic responses (15). Thus, the data are conflicting on the issue of whether administration of exogenous NO (iNO) is protective or damaging in the presence of hyperoxia in lung cells and

Abbreviations: CYP, cytochrome P450; EROD, ethoxyresourufin O-deethylase; iNO, inhaled nitric oxide; LW/BW, lung weight/body weight; ROS, reactive oxygen species; RT-PCR, reverse transcriptase PCR; WW/DW, wet weight/dry weight

DOI: 10.1203/01.pdr.0000199909.96576.7f 
animal models. Taken together, it appears that iNO, depending on its concentration, can either reduce or increase lung injury $(13,15)$, and developmental status of the animal also appears to influence the effects of iNO (15).

CYP enzymes belong to a superfamily of hemeproteins that play important roles in the metabolism of exogenous and endogenous chemicals (16). P450 enzymes, including CYP1A1, have also been implicated in the formation and further reactions of ROS, and may play a role in pulmonary oxygen toxicity (17-20). The CYP enzymes are developmentally regulated (21). Seventy percent of the CYP are constitutively expressed at one stage or another during development of animals and humans and one third of these belong to the CYP1-CYP3 families (21). In rodents, CYP1A1 is detected only at embryonic d 7, CYP1B1 on d 11, 15, and 17, whereas CYP1A2 is not expressed at all during embryonic and fetal development (21). However, these enzymes are inducible during prenatal and postnatal age by 3-methylcholanthrene or $\beta$-naphthoflavone (21).

NO appears to modulate the expression of CYP enzymes as well. A number of recent studies have shown inhibition of CYP enzymes by NO in vivo and in vitro (22-24), and this has been attributed to the binding of NO to the heme, leading to the inactivation of the enzyme. Down-regulation of CYP enzymes may also occur at the pretranslational level (23). Stadler et al. (24) have shown that NO inhibits CYP1A1/1A2 activities and expression in cultured hepatocytes.

There are several studies about the effects of iNO in conjunction with hyperoxia on lung injury in adult animals. However, there are fewer studies on the effects of iNO and hyperoxia in newborn animals. Furthermore, there is a paucity of information on the effects of these agents on the regulation of CYP enzymes in relation to lung injury. Therefore, the present study was carried out to begin to examine the influence of 20-40 ppm iNO, either alone or in combination with hyperoxia on lung injury and CYP1A expression. Specifically, we tested the hypothesis that exposure of newborn rats to hyperoxia, iNO, or iNO + hyperoxia, would modulate expression of pulmonary CYP1A1 in relation to acute lung injury.

\section{METHODS}

Animal experiments. Newborn Fischer 344 rats, delivered from timed pregnant rats, were maintained in room air or exposed to hyperoxia ( $>95 \%$ oxygen), iNO (20 or $40 \mathrm{ppm})$, or iNO (20 or $40 \mathrm{ppm})+$ hyperoxia for 24,48 , 72 , and $168 \mathrm{~h} \mathrm{(7} \mathrm{d),} \mathrm{after} \mathrm{which} \mathrm{the} \mathrm{animals} \mathrm{were} \mathrm{killed.} \mathrm{Purified} \mathrm{tap} \mathrm{water} \mathrm{and}$ food [Purina Rodent Lab Chow No. 5001 from Purina Mills, Inc. (Richmond, IN) were available ad libitum]. The mothers were rotated every $24 \mathrm{~h}$ to room air between each exposure so that possible toxicity to the mothers during nursing was minimal. The newborns and the mothers were placed in Plexiglas chambers, and oxygen and $\mathrm{NO}$ were mixed immediately before entry into the chambers and were delivered through a humidified circuit at a flow rate of 10 $\mathrm{L} / \mathrm{min}$. The rapid flow was used to minimize the transit time of $\mathrm{NO}$ in the chambers and thereby lower the concentration of nitrogen dioxide $\left(\mathrm{NO}_{2}\right)$. $\mathrm{FiO}_{2}, \mathrm{NO}$, and $\mathrm{NO}_{2}$ were monitored continuously by means of in-line analyzers at the outport of the chambers (25). This study was approved by Institutional Animal Care and Use Committee of Baylor College of Medicine.

Perfusion and tissue harvesting. At the termination of their respective exposures, 10 newborns from each group were anesthetized with sodium pentobarbital $(200 \mathrm{mg} / \mathrm{kg}$ i.p. $)$ and killed by exsanguination while under deep pentobarbital anesthesia. In six rats from each group, the lungs were perfused with PBS and microsomes were prepared for subsequent analyses of CYP1A1-dependent activities and immunoreactive protein contents in indi- vidual animals. In each of the remaining six animals from each group, the left lungs were inflated through the intratracheal catheter and were fixed at constant pressure $\left(20 \mathrm{~cm} \mathrm{H}_{2} \mathrm{O}\right)$ with zinc formalin, after which the lungs were embedded in paraffin for subsequent histologic and immunohistochemical analyses for assessing lung injury and CYP1A1 expression, respectively. The right lungs were used for subsequent RNA isolation and analyses.

Chemicals. Tris, sucrose, NADPH, BSA, ethoxyresorufin, glucose 6-phosphate, and glucose 6-phosphate dehydrogenase were purchased from Sigma Chemical Co. (St. Louis, MO). The primary MAb to CYP1A1 was a generous gift from Dr. P.E. Thomas. Goat anti-mouse IgG conjugated with horseradish peroxidase was from Bio-Rad laboratories (Richmond, CA). All real-time, reverse-transcriptase PCR (RT-PCR) reagents were from Applied Biosystems (Foster City, CA).

Preparation of microsomes and enzyme assays. Lungs were perfused with ice-cold PBS, pH 7.4. Lung microsomes were prepared by differential centrifugation, as reported previously (17), from individual animals. Protein concentrations and EROD (CYP1A1) activities in lung were assayed as we have described previously $(17,19,20)$.

Western blotting. Lung microsomes (20 $\mu \mathrm{g}$ of protein) prepared from individual animals were subjected to Western blotting, as described previously $(17,19,20)$. The proteins bands on the blots were detected by chemiluminescence after exposure to x-ray films (ECL plus detection, Amersham Pharmacia Biotech, Inc., Piscataway, NJ). Quantitation of the blots was accomplished by densitometric scanning of the X-ray films, as described previously $(19,20)$.

Real-time RT-PCR assays. Total RNA (50 ng) from lungs of air-breathing, hyperoxic, and iNO-exposed animals was subjected to one-step, real-time quantitative TaqMan RT-PCR. ABI PRISM 7700 Sequence Detection System (Applied Biosystems) was used for the RT-PCR reactions, as we have described in our recent paper (20).

Lung injury. LW/BW ratios and histologic assessment of lung damage were determined as reported previously (20). In addition, lung WW/DW ratios were measured as described by Garat et al. (13).

Lung immunohistochemistry. Cellular localization of pulmonary CYP1A1 was studied by immunohistochemistry, as described previously $(19,20)$.

Statistical analyses. All data are expressed as means \pm SE. Data from at least six individual animals was used to calculate the means. Multivariate ANOVA, followed by posthoc Newman-Keuls test, was used to assess significant differences arising from exposure to hyperoxia, iNO (20 or 40 ppm), or iNO (20 or $40 \mathrm{ppm})+$ hyperoxia for different time points. Fisher's $p$ test was used to analyze data on animal survival. $p$ Values $<0.05$ were considered significant.

\section{RESULTS}

In the present study, we tested the hypothesis that exposure of newborn rats to hyperoxia, iNO, or iNO + hyperoxia would modulate expression of pulmonary CYP1A1 isoforms in relation to acute lung injury.

Animal survival and lung injury. All animals exposed to hyperoxia $\left(\mathrm{FiO}_{2}>95 \%\right)$ or iNO $(20$ or $40 \mathrm{ppm})$ survived the entire duration of exposure [7 d (168 h)]. However, animals given a combination of hyperoxia and iNO (40 ppm) displayed decreased survival starting the third day of exposure. By d 7 (168 h), 3/10 animals had died (Table 1) $(p<0.05)$, and the surviving animals had respiratory distress. Animals exposed to a lower dose of iNO (20 ppm) in combination with hyperoxia resulted in $100 \%$ survival through the $7-d$ period (Table 1). Animals given iNO (40 ppm) + hyperoxia were more susceptible to acute lung injury than those exposed to hyperoxia or iNO alone, or to iNO $(20 \mathrm{ppm})+$ hyperoxia as determined by LW/BW ratios of the animals (Fig. 1). The iNO $(40 \mathrm{ppm})+$ hyperoxia group had the highest LW/BW ratios compared with the other conditions at each of the time points. Exposure of the animals to these regimens did not significantly alter the body weights for up to 72 h (Fig. 2). However, at the 168 -h time point, iNO (40 ppm) treatment resulted in a significant increase in body weight compared with the other 
Table 1. Survival rate (\%)

\begin{tabular}{lcccc}
\hline \multicolumn{1}{c}{ Treatment* } & $24 \mathrm{~h}$ & $48 \mathrm{~h}$ & $72 \mathrm{~h}$ & $168 \mathrm{~h}$ \\
\hline Room air & 100 & 100 & 100 & 100 \\
Hyperoxia & 100 & 100 & 100 & 100 \\
iNO (20 ppm) & 100 & 100 & 100 & 100 \\
iNO (20 ppm) + hyperoxia & 100 & 100 & 100 & 100 \\
iNO (40 ppm) & 100 & 100 & 100 & 100 \\
iNO (40 ppm) + hyperoxia & 100 & 100 & 90 & $70 \dagger$ \\
\hline
\end{tabular}

Newborn Fischer rats were either maintained in room air or exposed to hyperoxia ( $>95 \%$ oxygen $)$, iNO (20 ppm), iNO (20 ppm) + hyperoxia, iNO $(40 \mathrm{ppm})$, or iNO $(40 \mathrm{ppm})+$ hyperoxia for $24,48,72$, or $168 \mathrm{~h}$, and the survival rates of the animals were determined.

$* n=10$ animals per group.

$\dagger$ Statistically significant differences, as determined by Fisher's $p$ test, at $p$ $<0.05$ when compared to each of the other groups.

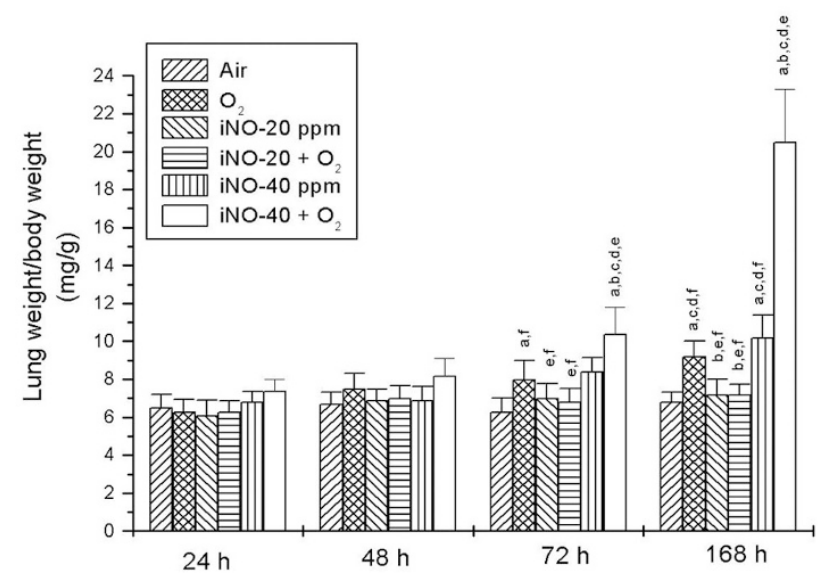

Figure 1. Effects of hyperoxia and iNO on LW/BW ratios. Newborn Fischer rats were maintained in room air (air) or exposed to hyperoxia, iNO (20 or 40 $\mathrm{ppm}$ ) or iNO (20 or $40 \mathrm{ppm})+$ hyperoxia for $24,48,72$, and $168 \mathrm{~h}$, and LW/BW ratios were measured. Multivariate ANOVA, followed by modified $t$ tests, were used to assess statistical significance between individual groups. Different at $p<0.05$ from room air (a), hyperoxia $(b)$, iNO (20 ppm) (c), iNO $(20 \mathrm{ppm})+$ hyperoxia $(d)$, iNO $(40 \mathrm{ppm})(e)$, and iNO $(40 \mathrm{ppm})+$ hyperoxia $(f)$. Values represent means $\pm \operatorname{SE}(n=6)$.

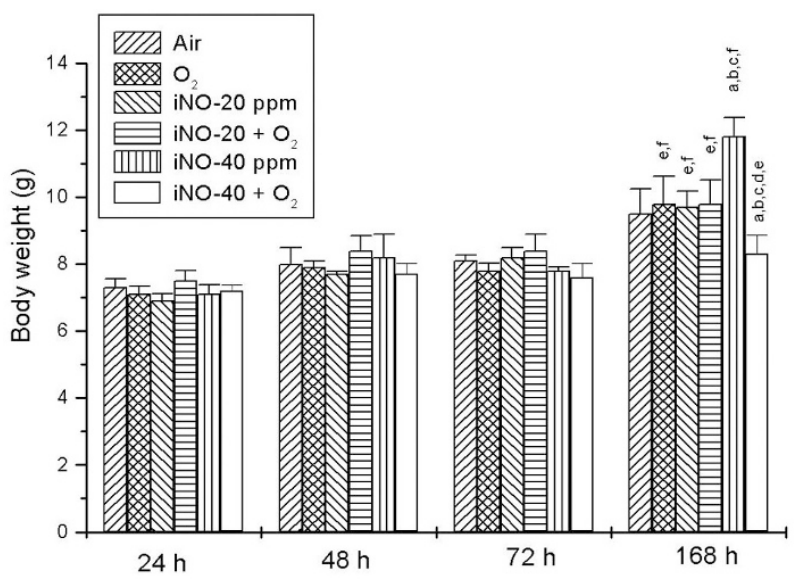

Figure 2. Effects of hyperoxia and iNO on lung wet/dry ratios. Newborn rats were exposed to different treatment regimens as described in legend to Figure 1 , and lung WW/DW ratios were determined. Statistical analyses were similar to that described in legend to Figure 1.

treatment groups, and iNO $(40 \mathrm{ppm})+$ hyperoxia treatment led to a significant decrease (13\%) in body weight (Fig. 2). The lung WW/DW ratios also showed trends that were similar to those of LW/BW ratios (Fig. 3), with animals exposed to iNO $(40 \mathrm{ppm})+$ hyperoxia showing the highest ratios after $7 \mathrm{~d}$ of exposure.

Histologic analyses of lung injury showed little change after exposure of newborn animals to the treatment regimens for $24 \mathrm{~h}$, compared with air-breathing animals (Fig. 4), except for the iNO $(40 \mathrm{ppm})+$ hyperoxia group, which showed some cellular debris and recruitment of inflammatory cells (Fig. 4F). No significant alterations in lung architecture were observed in animals exposed to hyperoxia, iNO (20 or $40 \mathrm{ppm})$, or iNO (20 or $40 \mathrm{ppm})+$ hyperoxia for up to $72 \mathrm{~h}$ (not shown). At the 168-h time point, the hyperoxic animals displayed slight lung injury, as evidenced by presence of inflammatory cells and cellular debris (Fig. $5 B)$. Animals given iNO (20 or $40 \mathrm{ppm})$ or iNO $(20 \mathrm{ppm})+$ hyperoxia did not show histologic evidence of lung damage, compared with air-breathing animals (Fig. 5). However, addition of iNO (40 ppm) to $95 \%$ oxygen resulted in significant lung damage, as evidenced by destruction of alveolar septa, presence of proteinaceous material in the alveolar spaces, pulmonary edema, and recruitment of inflammatory cells (Fig. 5F).

Pulmonary CYP1A1 expression. Hyperoxia or iNO (20 or $40 \mathrm{ppm})$ markedly induced pulmonary CYP1A1 activities (EROD) for up to $168 \mathrm{~h}$, compared with the room air controls (Fig. 6). Maximal induction ( $>2$-fold) by hyperoxia was noticed at $72 \mathrm{~h}$. Whereas EROD activities were still elevated in the hyperoxia, iNO (20 or $40 \mathrm{ppm})$, or iNO (20 ppm) + hyperoxia samples at $168 \mathrm{~h}$, induction by iNO (40 ppm) + hyperoxia had declined to control by $168 \mathrm{~h}$ (Fig. 6). To determine whether induction of EROD activities was paralleled by similar induction of CYP1A1 apoprotein levels, we performed Western blotting of the lung microsomal samples isolated from animals exposed to hyperoxia, iNO (20 or 40 ppm), and iNO (20 or 40 ppm) + hyperoxia (Fig. 7). Hyperoxia induced CYP1A1 levels for up to $168 \mathrm{~h}$, with maximal induction being at $72 \mathrm{~h}$ (4-fold), compared with room air controls (Fig. 8). iNO (20 or $40 \mathrm{ppm}$ ), by itself, induced

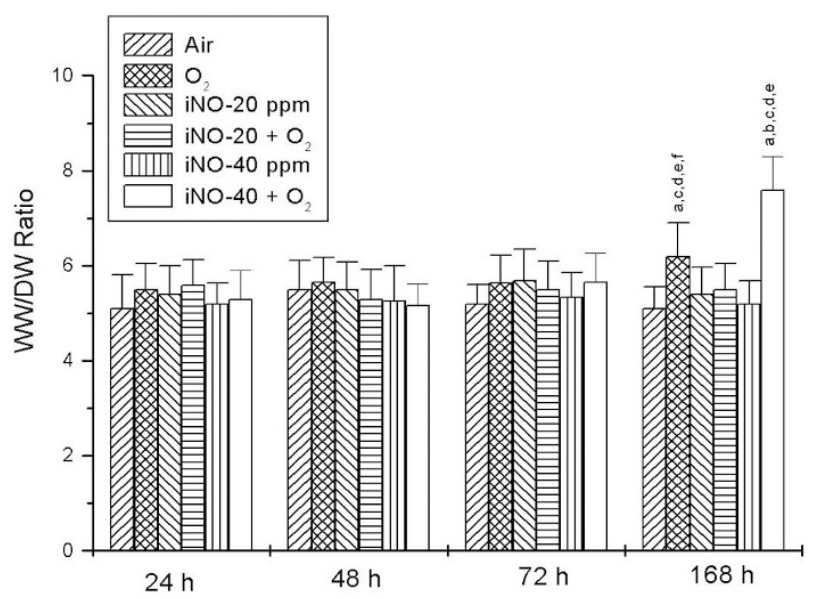

Figure 3. Effect of hyperoxia and iNO on body weights. Newborn rats were maintained in room air or exposed to hyperoxia or iNO as described in "Methods," and body weights of individual animals were recorded. Please see legend to Figure 1 for description of each experimental group. 


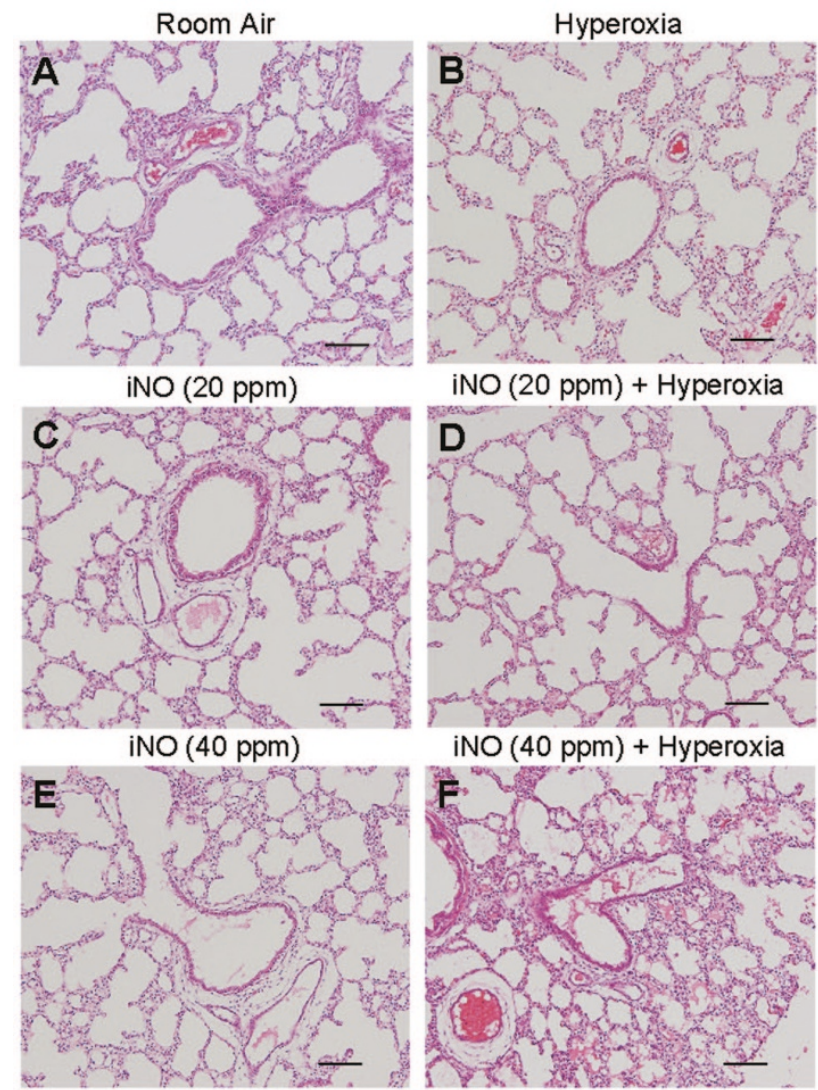

Figure 4. Lung injury assessment by histology at $24 \mathrm{~h}$. Newborn rats were maintained in room air $(A)$ or exposed to hyperoxia $(B)$, iNO (20 ppm) $(C)$, iNO $(20 \mathrm{ppm})+$ hyperoxia $(D)$, iNO $(40 \mathrm{ppm})(E)$, or iNO $(40 \mathrm{ppm})+$ hyperoxia $(F)$, and animals $(n=6)$ were killed after $24 \mathrm{~h}$. The lungs were inflated through the intratracheal catheter and were fixed at constant pressure $\left(20 \mathrm{~cm} \mathrm{H}_{2} \mathrm{O}\right.$ ) with zinc formalin, after which the lungs were embedded in paraffin for subsequent histologic analyses for assessing lung injury as described under "Methods." Bar length $=100 \mu \mathrm{m}$.

CYP1A1 expression at each of the time points. Combined exposure of the animals to iNO (20 ppm) + hyperoxia resulted in induction of CYP1A1 expression for up to $168 \mathrm{~h}$ (Figs. 7, 8). While treatment of animals with iNO + hyperoxia $(40 \mathrm{ppm})$ resulted in augmentation of CYP1A1 protein expression for up to $48 \mathrm{~h}$, the induction declined after $72 \mathrm{~h}$ of exposure (Fig. 7). The air-breathing controls showed gradual increase in the expression of CYP1A1, approaching significant levels by 168 h (Fig. 7), consistent with developmental changes.

Immunohistochemical studies showed expression of CYP1A1 in the air-breathing animals in airway epithelial cells, alveolar epithelial (type II), and endothelial cells. Fortyeight hours of hyperoxia induced CYP1A1 expression in endothelial cells and type II cells (Fig. 9). iNO (40 ppm) + hyperoxia treatment showed lower expression of CYP1A1 in these cell types than that observed in the hyperoxia-only group (Fig. 9). Similar to hyperoxia, iNO alone induced CYP1A1 expression in airway epithelial cells, alveolar epithelial cells, and endothelial cells (not shown).

Pulmonary CYP1A1 mRNA levels, as determined by realtime RT-PCR, were induced (10- to 40-fold) by hyperoxia, iNO (20 or $40 \mathrm{ppm})$, or iNO (20 ppm) + hyperoxia exposure
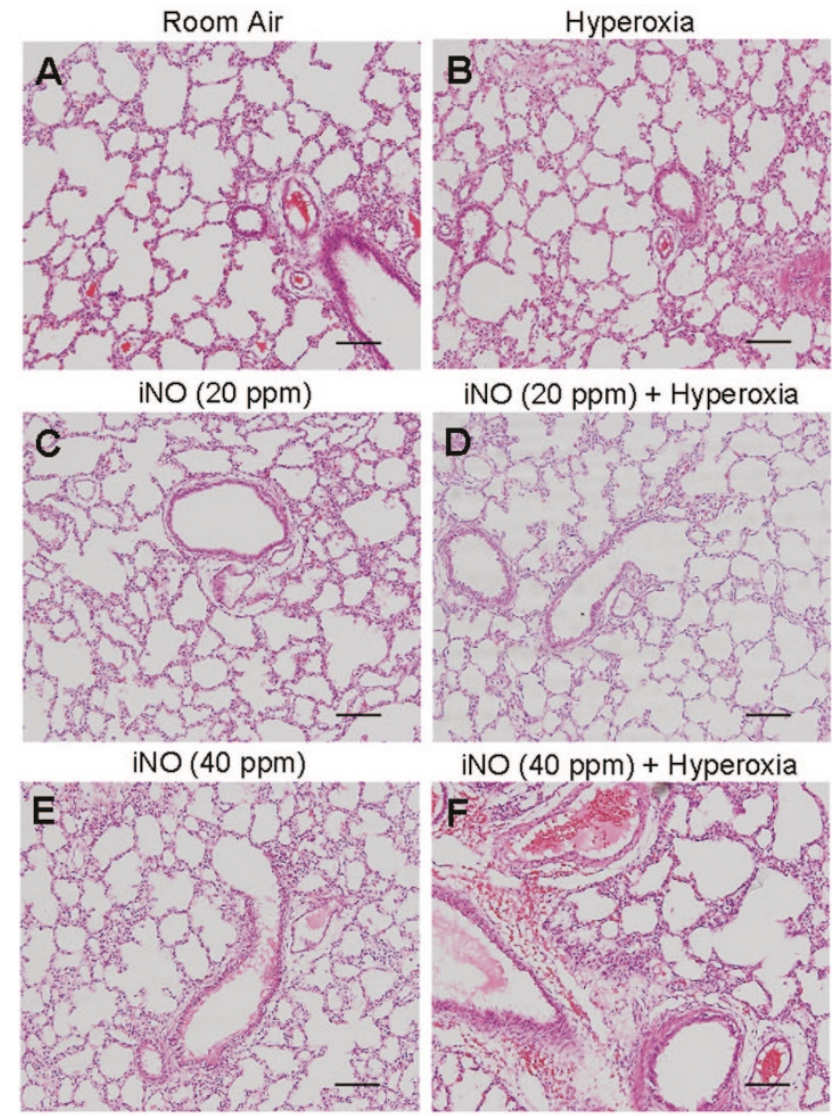

Figure 5. Lung injury assessment by histology at $168 \mathrm{~h}$. The protocol for treatment of animals with hyperoxia, iNO, and iNO + hyperoxia was identical to that described in the legend to Figure 4, except that the animals were killed at $168 \mathrm{~h}$. Panels $A-F$ are identical to those of Figure 4. Bar length $=100 \mu \mathrm{m}$.

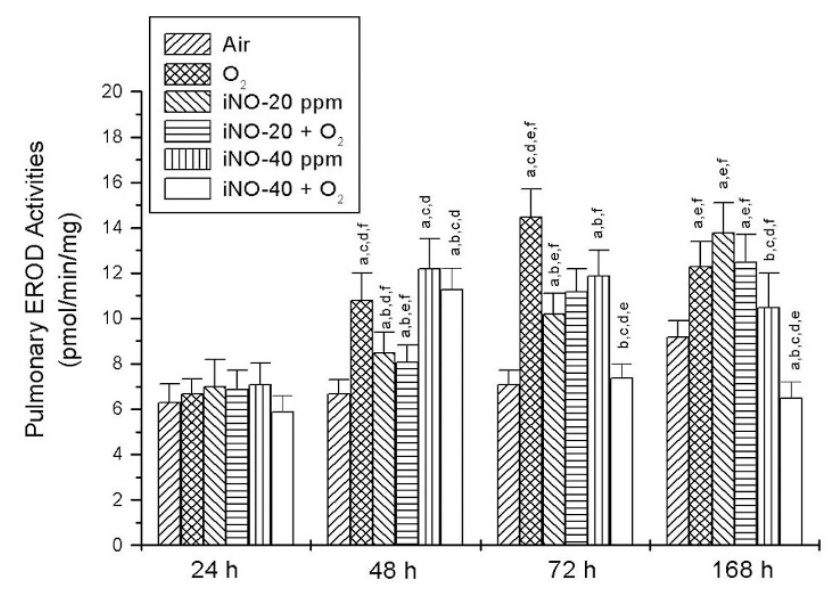

Figure 6. Effects of hyperoxia and iNO on pulmonary EROD activities. Newborn Fischer rats were maintained in room air (air) or exposed to hyperoxia, iNO (20 or $40 \mathrm{ppm})$, or iNO (20 or $40 \mathrm{ppm})$ + hyperoxia for 24 , 48,72 , or $168 \mathrm{~h}$, and pulmonary EROD activities were measured in the microsomes. Statistical analyses were performed and are presented as described in legend to Figure 1. All values represent means $\pm \operatorname{SE}(n=6)$.

for 24-168 h (Fig. 10). Hyperoxia + iNO (40 ppm) exposure resulted in significant induction in the CYP1A1 mRNA expression for up to $48 \mathrm{~h}$, but induction declined after $72-168 \mathrm{~h}$ (Fig. 10). 


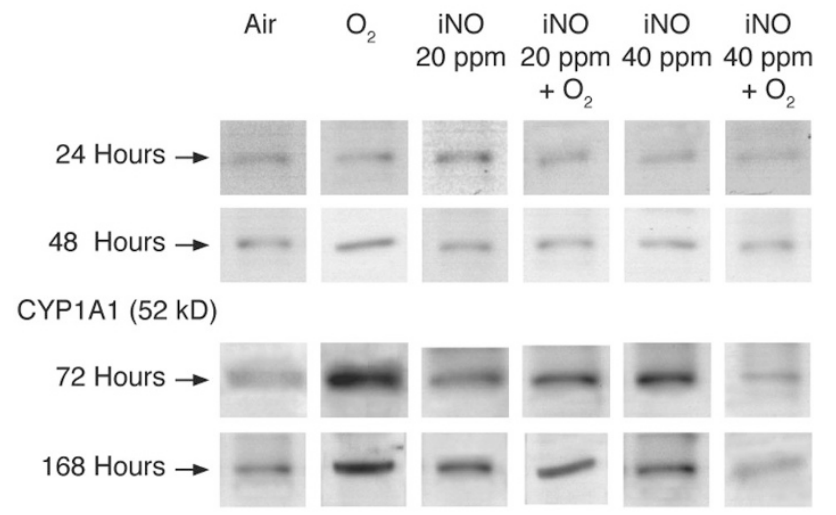

Figure 7. Effects of hyperoxia and iNO on pulmonary CYP1A1 apoprotein expression. Newborn Fischer rats were maintained in room air or exposed to hyperoxia, iNO (20 or $40 \mathrm{ppm})$, or iNO (20 or $40 \mathrm{ppm})+$ hyperoxia for 24 , 48, 72, and $168 \mathrm{~h}$, and pulmonary CYP1A1 expression was determined by Western blotting.

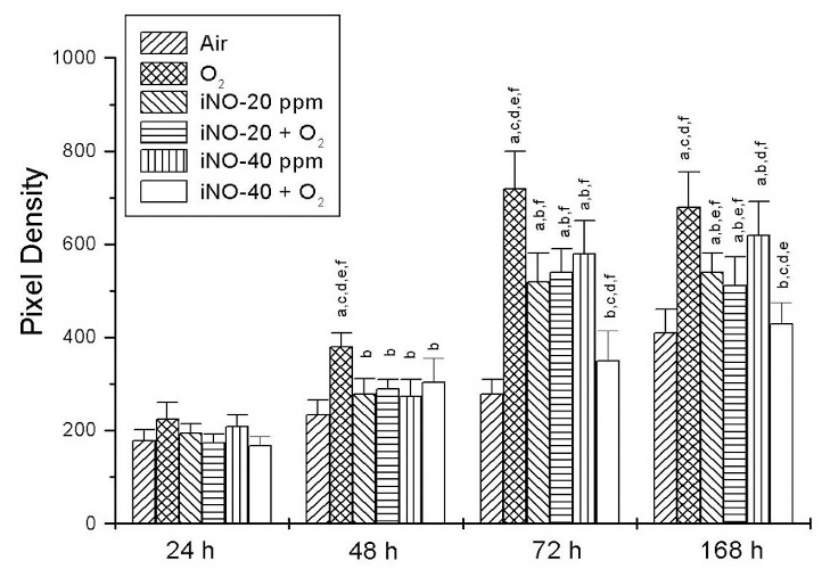

Figure 8. Effects of hyperoxia on pulmonary CYP1A1 apoprotein levels. The band intensities obtained from the Western blot experiments described in legend to Figure 7 were quantitated by densitometric analyses of the x-ray films of the blots. The treatment groups are indicated in the figure. Statistical analyses were performed and are presented as described in legend to Figure 1. All values represent means \pm SE $(n=6)$.

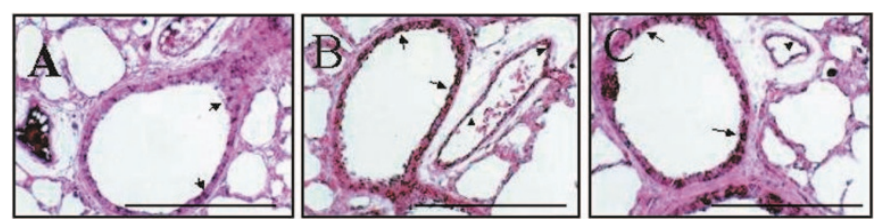

Figure 9. Representative lung sections for CYP1A1 immunohistochemistry from newborn rats. Newborn rats were maintained in air $(A)$, or exposed to hyperoxia $(B)$, or iNO $(40 \mathrm{ppm})+$ hyperoxia $(C)$ for $48 \mathrm{~h}$, as described in legend to Figure 1, and lungs were processed for immunohistochemistry as described under "Methods." Bar length $=50 \mathrm{~mm}$.

\section{DISCUSSION}

The major goal of the present study was to the determine the role of iNO, alone or in conjunction with hyperoxia, on lung injury and the possible modulation of pulmonary CYP1A1 enzyme caused by these agents in the newborn rat.

Our observation that only $70 \%$ of the animals exposed to iNO $(40 \mathrm{ppm})+$ hyperoxia survived $7 \mathrm{~d}$ of exposure (Table 1) suggests that the combined administration of these gases caused toxicity, cell death, and subsequent decreased survival

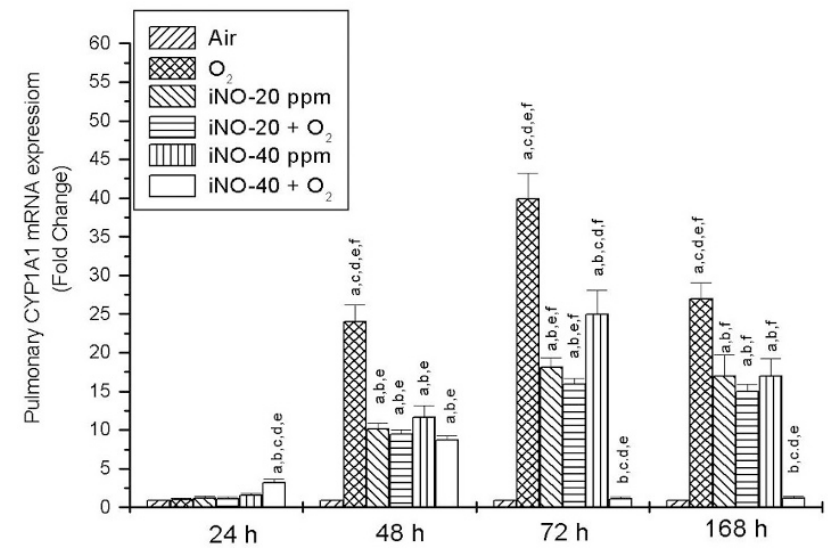

Figure 10. Real-time RT-PCR analysis of pulmonary CYP1A1 mRNA from newborn rats exposed to room air, hyperoxia, or iNO. Total RNA (50 ng) from lungs of air-breathing, hyperoxic, and iNO-exposed animals was subjected to one-step, real-time quantitative TaqMan RT-PCR. Data represent relative fold changes in CYP1A1 gene expression induced by hyperoxia, iNO (20 or $40 \mathrm{ppm}$ ), or iNO (20 or $40 \mathrm{ppm})+$ hyperoxia over room air controls. All data were normalized to their corresponding 18S mRNA contents, as described in "Methods.) Values represent means \pm SE of data from at least six individual animals. Letters denote statistically significant differences when fold induction was compared between ahyperoxia, ${ }^{b}$ iNO (20 ppm), ${ }^{\text {ciNO }}$ (20 ppm $)+$ hyperoxia, ${ }^{\mathrm{i}} \mathrm{iNO}(40 \mathrm{ppm})$, and ${ }^{\mathrm{e}} \mathrm{iNO}(40 \mathrm{ppm})+$ hyperoxia.

of this group of animals (Table 1) with lung injury. Interestingly, $100 \%$ of animals exposed to iNO (20 ppm) + hyperoxia survived $168 \mathrm{~h}$ of exposure (Table 1), suggesting that lowering the dose of iNO attenuated lung injury.

The increase in LW/BW ratios (Fig. 1) and WW/DW ratios (Fig. 3) in animals given iNO (40 ppm) + hyperoxia compared with those given hyperoxia, iNO (20 or $40 \mathrm{ppm}$ ) or iNO $(20 \mathrm{ppm})+$ hyperoxia (Fig. 1) suggests that iNO at $40 \mathrm{ppm}$ potentiates the pulmonary toxicity of oxygen. The fact that total body weights were not altered by any of the treatment regimens for up to $72 \mathrm{~h}$ suggests that the alterations in LW/BW ratios by hyperoxia, iNO, or iNO + hyperoxia were not due to changes in body weight. At the $168 \mathrm{~h}$ time point, iNO $(40 \mathrm{pm})+$ hyperoxia caused a modest $(13 \%)$ decrease in body weight, suggesting that the increase (300\%) in LW/BW ratio (Fig. 1) in this group compared with air-breathing animals was not due to a decrease in food consumption. This interpretation is supported by our studies on lung injury assessments by histology showing lung damage in the iNO (40 $\mathrm{ppm})+$ hyperoxia group at $168 \mathrm{~h}$ (Fig. 5E). While the hyperoxia group at $168 \mathrm{~h}$ showed some lung damage compared with air-breathing animals (Figs. 1, 3, and 5B), animals given iNO $(20 \mathrm{ppm})+$ hyperoxia displayed lung injury parameters that were not significantly different from airbreathing controls, suggesting that iNO (20 ppm) in conjunction with hyperoxia prevented oxygen-induced lung injury.

Our findings that iNO (40 ppm) potentiates hyperoxic lung injury were consistent with the findings of Rayhrer et al. (26), who showed that NO potentiates acute lung injury in an isolated rabbit lung model. Moreover, in newborn (3-d-old) rats, exposure to hyperoxia for 7 or $14 \mathrm{~d}$ results in significant lung injury, and treatment of hyperoxic animals with L-NAME $\left(\mathrm{N}^{\omega}\right.$-nitro-L-arginine methyl ester) attenuates lung injury (27), 
suggesting that increased generation of endogenous NO potentiates hyperoxia-induced lung injury in these newborns.

The marked increases in lung EROD activities (Fig. 1) caused by exposure to hyperoxia or iNO for $48-72 \mathrm{~h}$ indicates induction of CYP1A1, as EROD activities are relatively specific for CYP1A1 $(19,20)$. The newborn animals have very low basal levels of CYP1A1, and the mechanisms of induction of CYP1A1 by iNO or hyperoxia in the newborn animals are not clearly understood. Hyperoxia appears to induce CYP1A1 expression in adult rats and mice by Ah receptor-dependent mechanisms $(19,20)$, and it is possible that hyperoxia or iNO may induce CYP1A1 in the newborn rat through similar mechanisms. That modulation of EROD activities was paralleled by similar alterations in the apoprotein levels (Figs. 7 and 8) suggests that induction of CYP1A1 was due to new synthesis of the protein. Our observation (Fig. 9) that hyperoxia or iNO + hyperoxia induced CYP1A1 in airway epithelial cells and endothelial cells suggests cell-specific alterations in the expression of CYP1A1 by these agents.

The augmentation in lung CYP1A1 mRNA expression after $48-168 \mathrm{~h}$ of hyperoxia, iNO (20 or $40 \mathrm{ppm}$ ), or iNO (20 ppm) + hyperoxia exposure (Fig. 10) supported the hypothesis that induction of CYP1A1 activities was due, in part, to activation of CYP1A1 gene expression. Hazinski et al. (28) have shown induction of CYP1A1 mRNA by hyperoxia in cultured endothelial cells from lambs to be mediated by transcriptional mechanisms. The fact that the expression of CYP1A1 mRNA declined after $72 \mathrm{~h}$ of iNO (40 ppm) + hyperoxia treatment (Fig. 10) strongly suggests that the decline of EROD activities at this time point was due to down-regulation of CYP1A1 expression at the pretranslational level, presumably through mechanisms involving nuclear factor 1 (29).

The attenuation in the expression of CYP1A apoprotein between $72 \mathrm{~h}$ and $168 \mathrm{~h}$ of hyperoxia or iNO $(40 \mathrm{ppm})+$ hyperoxia may also have been due to loss of immunoreactivity or function via oxidative degradation of CYP1A1/1A2 by hyperoxia $(19,20)$. In fact, Paller and Jacob (30) have recently shown that P450 enzymes, upon degradation, can generate redox-active iron, which might induce lung injury through increased formation of Fenton-like reactions or by propagating oxidative stress and lipid peroxidation. Taken together, the data are consistent with the hypothesis that there is a link between pulmonary CYP1A1 expression and development of lung injury. Further studies to establish the mechanisms of modulation of CYP1A enzymes by hyperoxia and iNO in relation to lung injury are warranted inasmuch as they potentially could lead to new strategies aimed at preventing/treating hyperoxic lung injury in infants.

Acknowledgment. The authors thank Dr. Paul Thomas of the Rutgers University for providing us MAb against CYP1A1/1A2.

\section{REFERENCES}

1. Fisher AB 1980 Oxygen therapy. Side effects and toxicity. Am Rev Respir Dis 122:61-69

2. Bourbon J, Boucherat O, Chailley-Heu B, Delacourt C 2005 Control mechanisms of lung alveolar development and their disorders in bronchopulmonary dysplasia. Pediatr Res 57:38R-46R
3. Clark JM, Lambertsen CJ 1971 Pulmonary oxygen toxicity: a review. Pharmacol Rev 23:37-133

4. Neonatal Inhaled Nitric Oxide Group. 1997 Inhaled nitric oxide in full-term and nearly full-term infants with hypoxic respiratory failure. N Engl J Med 336:597-604

5. Kinsella JP, Truog WE, Walsh WF, Goldberg RN, Bancalari E, Mayock DE, Redding GJ, deLemos RA, Sardesai S, McCurnin DC, Moreland SG, Cutter GR, Abman SH 1997 Randomized, multicenter trial of inhaled nitric oxide and highfrequency oscillatory ventilation in severe, persistent pulmonary hypertension of the newborn. J Pediatr 131:55-62

6. Hoffman GM, Ross GA, Day SE, Rice TB, Nelin LD 1997 Inhaled nitric oxide reduces the utilization of extracorporeal membrane oxygenation in persistent pulmonary hypertension of the newborn. Crit Care Med 25:352-359

7. McCurnin DC, Pierce RA, Chang LY, Gibson LL, Osborne-Lawrence S, Yoder BA, Kerecman JD, Albertine KH, Winter VT, Coalson JJ, Crapo Grubb PH, Shaul PW 2005 Inhaled NO improves early pulmonary function and modifies lung growth and elastin deposition in a baboon model of neonatal chronic lung disease. Am J Physiol Lung Cell Mol Physiol 288:L450-L459

8. McElroy MC, Wiener-Kronish JP, Miyazaki H, Sawa T, Modelska K, Dobbs LG, Pittet JF 1997 Nitric oxide attenuates lung endothelial injury caused by sublethal hyperoxia in rats. Am J Physiol 272:L631-L638

9. Nelin LD, Welty SE, Morrisey JF, Gotuaco C, Dawson CA 1998 Nitric oxide increases the survival of rats with a high oxygen exposure. Pediatr Res 43:727-732

10. Pepke-Zaba J, Higenbottam TW, Dinh-Xuan AT, Wallwork J 1991 Inhaled nitric oxide as a cause of selective pulmonary vasodilation in pulmonary hypertension. Lancet 338:1173-1174

11. Howlett CE, Hutchison JS, Veinot JP, Chiu A, Merchant P, Fliss H 1999 Inhaled nitric oxide protects against hyperoxia-induced apoptosis in rat lungs. Am J Physiol 277:L596-605

12. Rubbo H, Radi R, Trujillo M, Telleri R, Kalyanaraman B, Barnes S, Kirk M, Freeman BA 1994 Nitric oxide regulation of superoxide and peroxynitrite-dependent lipid peroxidation. Formation of novel nitrogen-containing oxidized lipid derivatives. J Biol Chem 269:26066-26075

13. Garat C, Jayr C, Eddahibi S, Laffon M, Meignan M, Adnot S 1997 Effects of inhaled nitric oxide or inhibition of endogenous nitric oxide formation on hyperoxic lung injury. Am J Respir Crit Care Med 155:1957-1964

14. Lin YJ, Markham NE, Balasubramaniam V, Tang JR, Maxey A, Kinsella JP, Abman SH 2005 Inhaled nitric oxide enhances distal lung growth after exposure to hyperoxia in neonatal rats. Pediatr Res 58:22-29

15. Bhandari V 2003 The role of nitric oxide in hyperoxia-induced injury in the developing lung. Front Biosci 8:361-369

16. Guengerich FP 1990 Enzymatic oxidation of xenobiotic chemicals. Crit Rev Biochem Mol Biol 25:97-153

17. Couroucli XI, Welty SE, Geske RS, Moorthy B 2002 Regulation of pulmonary and hepatic cytochrome P4501A expression in the rat by hyperoxia: implications for hyperoxic lung injury. Mol Pharmacol 61:507-515

18. Gonder JC, Proctor RA, Will JA 1985 Genetic differences in oxygen toxicity are correlated with cytochrome P-450 inducibility. Proc Natl Acad Sci U S A 82:63156319

19. Sinha A, Muthiah K, Jiang W, Couroucli X, Barrios R, Moorthy B 2005 Attenuation of hyperoxic lung injury by the CYP1A inducer $\beta$-naphthoflavone. Toxicol Sci 87:204-212

20. Jiang W, Welty SE, Couroucli XI, Barrios R, Kondraganti SR, Muthiah K, Yu L, Avery SE, Moorthy B 2004 Disruption of the Ah receptor gene alters the susceptibility of mice to oxygen-mediated regulation of pulmonary and hepatic cytochromes P4501A expression and exacerbates hyperoxic lung injury. J Pharmacol Exp Ther 310:512-519

21. Hakkola J, Tanaka E, Pelkonen O 1998 Developmental expression of cytochrome P450 enzymes in human liver. Pharmacol Toxicol 82:209-17

22. Khatsenko OG, Gross SS, Rifkind AB, Vane JR 1993 Nitric oxide is a mediator of the decrease in cytochrome P450-dependent metabolism caused by immunostimulants. Proc Natl Acad Sci U S A 90:11147-11151

23. Khatsenko OG, Boobis AR, Gross SS 1997 Evidence for nitric oxide participation in down-regulation of CYP2B1/2 gene expression at the pretranslational level. Toxicol Lett 90:207-216

24. Stadler J, Trockfeld J, Schmalix WA, Brill T, Siewert JR, Greim H, Doehmer J 1994 Inhibition of cytochromes P4501A by nitric oxide. Proc Natl Acad Sci U S A 91:3559-3563

25. Nelin LD, Christman NT, Morrisey JF, Dawson CA 1996 Electrochemical nitric oxide and nitrogen dioxide analyzer for use with inhaled nitric oxide. J Appl Physiol 81:1423-1429

26. Rayhrer CS, Edmisten TD, Cephas CG, Tribble CG, Kron IL, Young JS 1998 Nitric oxide potentiates acute lung injury in an isolated rabbit lung model. Ann Thorac Surg 65:935-938

27. Radomski A., Sawicki G., Olson DM, Radomski MW 1998 The role of nitric oxide and metalloproteinases in the pathogenesis of hyperoxia-induced lung injury in newborn rats. Br J Pharmacol 125:1455-1462

28. Hazinski TA, Noisin E, Hamon I, DeMatteo A 1995 Sheep lung cytochrome P4501A1 (CYP1A1): cDNA cloning and transcriptional regulation by oxygen tension. J Clin Invest 96:2083-2089

29. Morel Y, Mermod N, Barouki R 1999 An autoregulatory loop controlling CYP1A1 gene expression: role of $\mathrm{H}(2) \mathrm{O}(2)$ and NFI. Mol Cell Biol 19:68256832

30. Paller MS, Jacob HS 1994 Cytochrome P-450 mediates tissue-damaging hydroxyl radical formation during reoxygenation of the kidney. Proc Natl Acad Sci U S A 19:7002-7006 